ANÁLISE REGIONAL DAS MESORREGIOES DO ESTADO DO PARANÁ NO FINAL DO SÉCULO XX

JANDIR FERRERA DE LIMA, LUCIR REINALDO ALVES, MOACIR Piffer e Carlos Alberto Piacenti

CUSTO NA DÍVIDA PÚBLICA INTERNA DA REDUÇĀO DA VULNERABILIDADE EXTERNA BRASILEIRA ATRAVESS DO AUMENTO DAS RESERVAS INTERNACIONAIS

ROBERTO MEURER

DETERMINAČÃO DE UM MODELO DE PREVISÃO UNIVARIADO PARA PREÇOS DE LEITE PAGOS AOS PRODUTORES EM SANTA CATARINA

ARLei LUiz Fachinello e Mirian Rumenos Piedade Bacch!

VIABILIDADE DE ESTRATÉGIAS DE HEDCE COM CONTRATOS FUTUROS DE BOI GORDO NO BRASIL DIANA de MEDEIROS BAPTISTA E DANILO ROLIM DIAS DE AGUIAR

ATAQUES ESPECULATIVOS E CRISES CAMBIAIS NA ARGENTINA E NO BRASIL: UMA ANÁLISE COMPARATIVA KELLEN FrAGa DA SIIVA E FERnANDO FERRARI FILHO

A TEORIA DOS FUNDOS DE EMPRÉSTIMOS: UM ESTUDO DOS MODELOS AGREGADOS NEOCLÁSSICO E KEYNESIANO

ALAIN HERSCOVICI

CRIME ECONÔMICO NO PARANÁ: UM ESTUDO DE CASO SALETE POLONIA BoriLLI E PERY Francisco AsSIS SHIKIDA

APLICAÇĀO DA NOVA ECONOMIA INSTITUCIONAL AO AMBIENTE PORTUÁRIO: ANÁLISE DOS CUSTOS DE TRANSAÇĀO NO PORTO DE SANTOS

CinTIA RETZ LUCCI, ALCINDO FERNANDES GONÇALVES E

ROBERTO FAVA SCARE

REDUÇÃO DE MANDATOS LEGISLATIVOS: O DEBATE ADORMECIDO

Francisco josé de Queiroz PINHeiro, Charles lima de ALMEIDA E TITO BELCHIOR SILVA MOREIRA

ANÁLISE ECONÔMICA E AMBIENTAL DE SISTEMAS DE TERMINACCÃO DE SUINNOS COM A APLICACCÃO DOS CONUUNTOS FUZZY

JULIO EDUARDo ROHENKOHL, ORLANDO MARTINELLI E MARCOS ALVES DOS REYS

RESENHA: THE GLOBAL EVOLUTION OF INDUSTRIAL RELATIONS EVENTS, IDEAS AND THE IIRA

CARLOS HENRIQUE HoRN
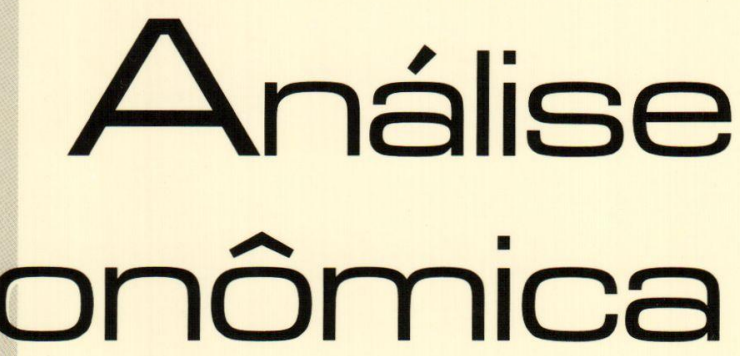


\section{A Revista Análise Econômica agradece a colaboração dos pareceristas dos números 45 e 46 , abaixo relacionados}

Abraham Benzaquen Sicsu

Adelar Fochezalto

Ademar Ribeiro Romeiro

Ademir Clemente

Alexandre Stamford da Silva

Ana Lucia Kassouf

Andre Luis Rossi de Oliveira

Andre Tosi Furtado

Andrea Sales Soares de Azevedo Melo

Angela Antonia Kageyama

Antonio Wilson Ferreira Menezes

Armando João Dalla Costa

Bernardo Mueller

Carlos Frederico Leao Rocha

Claudio Roberto Fóffano Vasconcelos

Cláudio Diissey Shikida

Clesio Lourenco Xavier

Dullio de Avila Berni

Eliezer Martins Diniz

Emerson Fernandes Marçal

Eugenio Lagemann

Fernando Ferrari Fitho

Francisco Casimiro Filho

Franklin Leon Peres Serrano

Frederico Gonzaga Jayme Jr.

Geraldo Edmundo Silva Jr.

Helder Ferreira de Mendonça
Helder Queiroz Pinto Junior Izabel Cristina Takitane

Joaquim José Martins Guilhoto

Joilson Dias

Jose Gabriel Porcile Meirelles

José Rubens Damas Garlipp

Julio César de Oliveira

Lovois de Andrade Miguel

Marcelo Savino Portugal

Marcio Holland de Brito

Marco Aurelio Crocco Afonso

Marcos Costa Holanda

Mônica Viegas Andrade

Paulo Dabdab Waquil

Paulo Sergio Fracalanza

Pedro Bandeira

Pedro Valentim Marques

Pery Francisco Assis Shikida

Renato Leite Marcondes

Roberto Camps Moraes

Ronald Otto Hilbrech

Ronaldo de Albuquerque e Arraes

Ronaldo Seroa da Motta

Thompson Almeida Andrade

Tito Belchior Silva Moreira

Valmor Marchetti

Vladimir Kuhl Teles 


\title{
Crime econômico no Paraná: um estudo de caso
}

\author{
Salete Polonia Borilli* \\ Pery Francisco Assis Shikida**
}

\begin{abstract}
Resumo: O objetivo deste trabalho consiste na análise do crime econômico no Paraná, por meio de um estudo de caso nas Penitenciárias Central, Estadual e Feminina de Piraquara, a partir de dados primários obtidos via aplicação de questionários/entrevistas a réus já julgados e condenados por crimes econômicos. Como corolário deste estudo, não se rejeitou a hipótese de que os criminosos migraram para as atividades ilegais na esperança de os ganhos esperados superassem os riscos da atividade. A opção pela prática do crime de natureza econômica é uma decisão individual, tomada racionalmente, com ou sem influências de terceiros, em face da percepção de custos e beneficios, assim como os indivíduos fazem em relação a outras decisōes de natureza econômica.
\end{abstract}

Palavras-chave: crime econômico, penitenciárias, escolha racional.

\begin{abstract}
The objective of this work consists of an analysis of the economic crime of Paraná State through a case study carried out in the Central, Feminine and State Penitentiaries in the city of Piraquara, based on primary data collected from questionnaires/interviews which were applied to previously judged and condemned defendants for economic crimes. In this research, the hypothesis that the criminals' migration to illegal activities was in the hope of earning more than the risks of the activity was not rejected. The option for the practice of crime of economic nature is a rational and individual one, with or without the influence of others, in face of the perception of costs and benefits such as those made by individuals in relation to others decisions of economic nature.
\end{abstract}

Keywords: economic crimes, penitentiaries, rational choice.

JEL: Z19

- Os autores são gratos aos pareceristas desta Revista pelas suas proficuas sugestões.

* Mestre em Desenvolvimento Regional e Agronegócio pela UNIOESTE - Toledo. Professora Assistente da Universidade Paranaense - UNIPAR - Toledo. Av. Parigot de Souza, 3636. CEP: 859.03-170. Toledo (PR). E-mail: borilli@ certto.com.br

* Doutor em Economia Aplicada pela ESALQ/USP. Professor Associado do Curso de Economia e do Mestrado em Desenvolvimento Regional e Agronegócio da UNIOESTE - Toledo. Rua da Faculdade, 645 CEP: 85.903-000. Toledo, PR. Pesquisador do CNPq e do GEPEC - Grupo de Pesquisa em Agronegócio e Desenvolvimento Regional.E-mail: pfashiki@unioeste.br Recebido em dezembro de 2005. Aceito em agosto de 2006. 


\section{Introdução e formulação do problema}

O objetivo deste trabalho consiste na análise do crime econômico no Paraná por meio de um estudo de caso nas Penitenciárias Central de Piraquara (PCP), Estadual de Piraquara (PEP) e Feminina de Piraquara (PFP), a partir de dados primários obtidos via aplicação de questionários/entrevistas a réus já julgados e condenados por crimes econômicos. A escolha dessas três unidades prisionais deu-se pelas características intrínsecas das unidades penais, pois as instituições supracitadas se identificam por abrigar presos que necessitam de estabelecimentos com segurança máxima, para proteção da sua própria integridade física, e em razão da necessidade de segurança da coletividade. Vale dizer que estas são as maiores unidades penais construídas pelo Governo do Estado do Paraná, em parceria com o Ministério da Justiça.

Ao analisar o crime sob as circunstâncias econômicas da prática criminosa, espera-se contribuir para a busca de uma maior compreensão sobre o tema. A pertinência em relação à escolha do assunto baseia-se ainda em estudos recentes [sobre isto, ver: Brenner (2001), Schaefer e Shikida (2001), Borilli (2001), Balbinotto Neto (2003), Engel (2003), Fernandez (2003) e Shikida $(2005)^{1}$ ], que constataram que o crime econômico é um dos grandes problemas da sociedade.

Para Ib Teixeira (2005), no Brasil gastam-se cerca de $\mathrm{R} \$ 37$ bilhōes por ano para proteger o cidadão contra os crimes, mesmo assim, a fama de insegurança no Brasil persiste, o que leva o país a perder muito dinheiro. Por exemplo, perde-se com a atrofia do setor turístico, seriamente afetado pelas questōes da segurança, embora cerca de um milhão de pessoas trabalhem como vigilantes, quase a metade clandestina. Outrossim, em dias de parco crescimento do Produto Interno Bruto (PIB), "o faturamento de empresas de segurança privada e vigilância eletrônica pode chegar a $R \$ 8$ bilhões e a perspectiva é cada vez melhor, com taxas de crescimento de $10 \%$ ao ano.

Embora Becker (1968, p.170) tenha exposto que '[...] 'crime' is an economically important activity or "industry', notwithstanding the almost total neglect by economists", atualmente, alguns economistas têm demonstrado interesse por este problema, posto que o aumento da criminalidade pode arrefecer o nivel de atividade econômica de uma região, à medida que desestimula novos investimentos, os preços dos produtos são majorados com a incorporação dos custos com a segurança, entre outros (BORILLI e SHIKIDA, 2002). Isso sem considerar que parcela dos recursos e agentes produtivos atuantes no crime poderiam estar sendo alocados no setor produtivo lícito da

\footnotetext{
${ }^{1}$ Para uma revisita à literatura sobre a economia do crime, sugere-se ver: Shikida (2005).
} 
economia, gerando benefícios para a sociedade como um todo (FERNANDEZ, 2003).

Mas, o que vem a ser crime econômico ou lucrativo? Afora a questão jurídica, o crime pode ser classificado em dois grupos: o lucrativo (ou econômico) e o não-lucrativo (ou não-econômico) (BECKER, 1968). Como exemplos para o crime econômico têm-se: furto, roubo ou extorsão, usurpação, estelionato, receptação, crimes contra a propriedade imaterial, contra a fé pública, contra a administração pública, tráfico de entorpecentes; para o caso do crime não-econômico têm-se todos aqueles não incluídos no primeiro caso como, por exemplo, homicídio, estupro, abuso de poder, tortura etc.

Becker (1968) realça que há crimes que objetivam tão somente a apropriação de recursos econômicos, ou seja, ganhos pecuniários, usando ou não o atributo da violência. Nesse sentido, o criminoso econômico pode ser encarado como um "empresário", o qual é descrito por Schaefer e Shikida (2001) como um agente que irá organizar a sua produção, reunindo os fatores de produção disponiveis, e assumindo os riscos inerentes à atividade criminal. As expectativas do "empresário" criminoso também são de auferir lucro ou prejuízo. No caso de insucesso de uma operação ilegal, o prejuizo pode significar punições previstas no Código Penal.

Se o crime lucrativo faz parte da questão econômica, sendo inclusive objeto de estudo das Ciências Econômicas, as questões nucleares que emergem desta contextualização resumem-se em: quais as circunstâncias socioeconômicas da escolha ocupacional entre o setor legal e ilegal da economia, e por que os individuos decidem praticar crimes econômicos? Analisar esses aspectos para ưma amostra de réus - julgados e condenados - oriundos da PCP, PEP e PFP, a partir de dados - primários obtidos via aplicação de questionário seguido de entrevista, podérá contribuir para elucidar questões que outros delineamentos metodológicos não permitem inferir. Reconhece-se, portanto, a importância e a necessidade do estudo científico como ferramenta para a elaboração e a implementação de políticas de prevenção e combate à criminalidade, com um aspecto diferente, as causas e imbricações da criminalidade lucrativa são explicitadas e discutidas pelo criminoso.

Isto posto, a hipótese a ser testada neste artigo, que remonta à teoria de Becker (1968), é a seguinte: os indivíduos migram para as atividades ilegais na esperança de que os ganhos esperados superem os riscos da atividade. Destarte, a opção pelo crime econômico é uma decisão individual tomada racionalmente, em face da percepção de custos e beneficios, assim como os indivíduos fazem em relação a outras decisões cotidianas. 
Além desta breve introdução e formulação de problema, este trabalho subdivide-se em três seções. A primeira seção apresenta os procedimentos metodológicos utilizados, na segunda seção, apresentam-se os resultados pertinentes à aplicação de questionários via entrevistas na PCP, PEP e PFP. As considerações finais sumariam a pesquisa.

\section{Procedimentos metodológicos}

Este trabalho trata-se de um estudo de caso, caracterizando-se pela identificação dos fatores que determinam ou que contribuem para a ocorrência dos fenômenos analisados. Este tipo de pesquisa pode ser derivado tanto de constatações e percepções que têm como norte o desenvolvimento, esclarecimento ou modificação de conceitos e idéias, como de descrição das características de determinada população ou fenômeno (GIL, 2000; YIN, 2001).

Para o desenvolvimento deste trabalho, utilizou-se, como técnica principal, a abordagem qualitativa (GODOY, 1995). Esta abordagem relaciona-se ao fato de contribuir para o entendimento da economia do crime a partir de observações coletadas por meio de dados primários, obtidos via aplicação de questionários/entrevistas a réus já julgados e condenados por crimes econômicos (BECKER, 1999).

Outrossim, esta pesquisa baseou-se em um tipo de amostragem não probabilística, rotulada como amostragem possível ou por acessibilidade (GIL, 2000). Não é um método considerado rigoroso do ponto de vista estatístico, porém, neste estudo, é o entrevistado que decide responder ou não às perguntas a ele dirigidas; particularmente, sempre há criminosos que não estão dispostos a colaborar, por diversas razões (receio de que a pesquisa possa comprometer suas futuras ações e parceiros, de que a pesquisa seja um instrumento do Estado para prejudicá-lo etc.).

Não obstante, a técnica utilizada para a obtenção dos dađos permitiu maior flexibilidade, por possibilitar o ajustamento aos mais diversos tipos de problemas e de informantes, aprofundando-se, caso fosse necessário, em dúvidas pontuais, permitindo ao pesquisador detectar informações que estavam além das respostas dadas pelos entrevistados. Dessa forma, o contato direto do pesquisador com o seu objeto possibilitou explorar ao máximo a temática estudada (economia do crime), de modo a obter não apenas os dados inerentes à aplicação do questionário, mas o feeling do entrevistado. O tempo médio de cada entrevista para a aplicação do questionário foi de cer a de 30 minutos. A seçāo seguinte apresenta os resultados e a discussão. 


\section{Resultados e discussão}

No total, foram entrevistados 262 individuos (144 na PCP, 65 na $\mathrm{PEP}$ e 53 na $\mathrm{PFP}$ ), isto significa, em termos gerais, aproximadamente $58 \%$ do universo disponível para a pesquisa - depois de subtraído o crime não econômico, o crime econômico de monta relativamente menor em termos monetários, de pena e caracterização do banditismo, ${ }^{2}$ e os que não quiseram responder -, o que é aceitável para este tipo de pesquisa (GIL, 2000).

Antes de entrar nos resultados propriamente ditos, cabe considerar que as análises estatísticas serão feitas para as 262 entrevistas no seu todo, sem separação por unidades pesquisadas (PCP, PEP e PFP). Tal prática decorre da necessidade de resguardar o anonimato dos entrevistados (por sugestão de Diretores das Penitenciárias, juízes e pessoas ligadas, direta e indiretamente, à atividade do direito criminal, recomendou-se a exposição de dados da forma que será feito na seqüência deste trabalho).

\subsection{Perfil dos entrevistados}

Quanto aos principais aspectos, referentes aos dados gerais extraídos via aplicação do questionário através de entrevista com os detentos julgados e condenados por crimes econômicos, observou-se que 79,77\% dos casos pertencem a individuos do sexo masculino e $20,23 \%$ do sexo feminino. Esses dados acompanham o contexto nacional, onde a predominância prisional é do sexo masculino.

Outrossim, estudos realizados por Lemgruber (2000); sobre a criminalidade feminina, têm demonstrado o seu crescimento nos últimos anos, decorrente principalmente da maior participação feminina nas diversas atividades socioeconômicas, o que porribilitou novas oportunidades, inclusive a inserção no mundo do crime.

Além da questão do sexo, o perfil dos entrevistados ressalta também uma maioria de cor branca $(74,81 \%)$, majoritariamente jovens de até 28 (85,49\%), oriundos do próprio Paraná - meio urbano $(67,17 \%)$, e tementes à Deus $(69,84 \%$ disseram serem católicos, $13,74 \%$ evangélicos, $0,38 \%$ espíritas, $0,38 \%$ protestantes, $2,3 \%$ pertencentes a outras religiões, sendo que $13,36 \%$ declararam não possuir religiāo). ${ }^{3}$

2 Procurou-se caracterizar, nesta amostra, os perfis de "grandes" assaltantes, seqüestradores, traficantes etc. Para a entrevista, por exemplo, se havia um "comando" do tráfico, preferiu-se entrevistar o seu "comandante", nāo o "comandado", ou seja, foram separados, dentre os crimes econômicos, aqueles cujas penas foram consideradas elevadas devido à tipicidade de suas ações.

3 Dos que responderam que possuíam religiāo, 40,84\% disseram ser praticantes e $59,16 \%$ disseram não ser praticantes na época da prática do crime. Constatou-se ainda que $24,81 \%$ dos entrevistados mudaram de religiāo após a sua reclusāo no sistema penitenciário 
Relativizando, no Estado do Paraná, a proporção de brancos é de $75,9 \%$; em seguida, aparecem a cor parda $(20,8 \%)$, preta $(2,2 \%)$ e amarela $(1,3 \%)$ e em relação à distribuição etária para efeito de cotejo com dados da população paranaense por grupos de idade, observa-se que $17,9 \%$ desta encontra-se na faixa de 20 a 29 anos, ou seja, há um viés expressivo na migração dos jovens para a atividade criminal, posto a comparação de $85,49 \%$ vis-à-vis a 17,9\% (IBGE, 2001). Esta distribuição segue uma tendência nacional e regional, que diz que o maior número de praticantes de crimes são jovens. Andrade e Lisboa (2000a), por exemplo, chamam a atenção para o fato das pessoas jovens migrarem mais facilmente para as atividade ilegais, enquanto os mais velhos apresentam menor mobilidade entre atividades legais e ilegais.

\subsection{Análise das questões socioeducacionais dos entrevistados}

Quanto ao nível de escolaridade, constatou-se que $4,2 \%$ dos entrevistados não possuem instrução, 80,92\% têm apenas o ensino fundamental $-1^{\circ}$ grau $-, 14,50 \%$ o ensino médio $-2^{\circ}$ grau - e apenas $0,38 \%$ têm ensino superior, o que sugere que maiores níveis educacionais podem vir a coibir e/ou tolher a criminalidade.

A questão educacional deve ser correlacionada com os dados da escolaridade do país, em que $13,8 \%$ da população com mais de 15 anos de idade são analfabetos, outros 30,5\% são analfabetos funcionais, ou seja, pessoas que tiveram menos de quatro anos de escolaridade, sabem ler e escrever de maneira rudimentar, mas são incapazes de entender textos mais longos (IBGE, 2001). Em relação ao grau de escolaridade dos encarcerados, estudo realizado por Brandt (1986) demonstrou que 3\% da população encarcerada no Brasil é analfabeta. No entanto, nestes aspectos, observa-se que o fato de ser analfabeto não é um elemento essencial para a criminalidade, pois a especificidade do crime a ser cometido determina os pré-requisitos para o recrutamento dos novos integrantes para o mundo do crime, ou seja, a seleção é feita de acordo com a especificidade do crime e da vítima (ADORNO et al., 1995).

Vale dizer que $85,12 \%$ dos entrevistados que apresentaram nível de escolaridade de até o ensino fundamental ( $1^{\circ}$ grau) apresentaram variaçōes no tocante ao tipo de crime cometido, porém, para os 39 presos $(14,88 \%)$, com maiores níveis educacionais, ensino médio ( $2^{\circ}$ grau) e ensino superior, observaram-se práticas criminosas mais audaciosas e com nível de organização e planejamento mais complexo. Assim, a menor incidência de analfabetos na criminalidade pode estar relacionada às exigências técnicas do crime, onde planos mais elaborados fazem da educação um requisito importante para a execução das tarefas. 
Dentre os motivos relatados pelos entrevistados para justificar a interrupção/paralisação dos estudos, que resultaram na baixa escolaridade, destacam-se os fatores de ordem socioeconômica, em que a necessidade de contribuir na renda familiar foi citada por $32,82 \%$ dos entrevistados; inadaptação escolar - falta de afinidade - por 16,41\%; o envolvimento com o crime, drogas e delinqüência por $15,65 \%$ e motivos relacionados a casamento e/ou união estável foi citado por 10,68\% dos entrevistados. Ressalta-se que o item familiar - desagregação da família, descaso para com a educação e falta de apoio - foi mencionado por $17,56 \%$; a falta de estrutura educacional e a dificuldade de acesso por $6,12 \%$; a influência de terceiros foi mencionada por $4,58 \%$; e outros motivos representaram $11,45 \%$ (entre esses outros motivos ressaltam-se questões relacionadas à metodologia pedagógica utilizada pelos professores, atritos entre colegas, e desmotivação). Assim, “[...] estão se reunindo em galeras ou quadrilhas, os homens jovens [...] que, após várias repetências, deixaram a escola e não conseguiram o nível educacional cada vez mais necessário no mercado de trabalho da economia globalizada" (ZALUAR, 2004, p. 201).

\subsection{Estrutura familiar dos entrevistados}

Em relação à estrutura familiar dos entrevistados, constatou-se que mais da metade, ou seja, 51,58\%, encontravam-se na condição de solteiros, divorciados, separados ou viúvos, enquanto que, na condição de casados, amasiados ou concubinos, encontravam-se $48,42 \%$ dos entrevistados. No entanto, cabe frisar, quanto à convivência marital dos entrevistados, dos que declararam viver com companheiro(a)s, $31,68 \%$ disseram que já tiveram outras uniões desfeitas, anteriores à época da prática do crime.

Decorrente das informações coletadas, tem-se que a família, enquanto um dos alicerces do bom andamento da sociedade, não está sendo uma aliada no combate ao crime e/ou repasse dos bons costumes aos seus membros. Entrementes, faz-se necessária uma ressalva neste ponto, pois, dos 16,42\% entrevistados que estavam na condição de "sozinhos", ou seja, sem família, a ausência desta foi um motivador adicional para a atividade criminal. Deriva-se daí uma importante asserção, qual seja: a de que o que importa na relação família-crime não é a sua simples composição, mas, sim, a inter-relação existente entre os membros que a compõem, no sentido de repassar os bons costumes aos seus membros.

Considerando que a maioria dos criminosos entrevistados são jovens, pertencendo a faixa etária entre os 18 a 28 anos, faz-se necessária a análise das condições socioeconômicas da estrutura familiar 
dos mesmos, ou seja, as condições de empregabilidade, escolaridade, profissão/ocupação e situação marital dos pais.

Quanto a empregabilidade dos pais, constatou-se que $73,67 \%$ dos mesmos encontravam-se empregados na época da prática do crime dos filhos (entrevistados). Entretanto, a análise das variadas ocupações dos pais sugere que a renda seja, em geral, moderada, considerando o nível de escolaridade. Com efeito, no que tange ao nível de escolaridade dos pais dos entrevistados, tem-se que $29,78 \%$ não possuíam instrução, $62,59 \%$ possuíam apenas o ensino fundamental ( $\left.1^{\circ} \mathrm{grau}\right), 4,58 \%$ o ensino médio ( $2^{\circ}$ grau), e $3,05 \%$ possuíam o ensino superior.

Ainda em relação aos pais dos entrevistados, tem-se que $49,62 \%$ encontravam-se casados na época da prática do crime do filho (entrevistados), e que $50,38 \%$ das uniões já haviam sido desfeitas.

A questão da estrutura familiar correlacionada com a criminalidade, segundo dados da pesquisa, permite dizer que $37,78 \%$ possuíam antecedentes criminais, enquanto que $(62,22 \%)$ não possuíam antecedentes criminais na família. Importante é ressaltar que, entre os que possuíam antecedentes criminais, o laço de parentesco com o entrevistado era, na sua maioria, de pai, irmãos ou primos.

A relação dos entrevistados com o uso de drogas mostrou-se significativa nesta pesquisa, pois a maioria $(60,68 \%)$ disse ser fumante, e $57,25 \%$ faziam uso, regularmente, de bebida alcoólica. Por outro lado, $53,44 \%$ declararam fazer uso de drogas ilícitas - maconha, cocaína, crack - na época da prática do crime. Destes, 15,27\% disseram que ainda (na data da entrevista) consumiam drogas, embora encarcerados em regime fechado.

Neste contexto, destaca-se a função da estrutura familiar - composta por proceșsos de relaçōẹs intrafamiliares, aspectos econômicos, valores morais, éticos -, em que a diversidade e a interdependência revitalizam e controlam, inibindo a tendência ao crime. O enfraquecimento destes mecanismos de controle, exercidos naturalmente pelas pessoas que compõem a estrutura familiar, pode levar à desorganização social, que pode estar diretamente relacionada ao problema da criminalidade.

\subsection{Tipologia dos crimes praticados pelos entrevistados}

As diferenças de interesse material e a possível renda auferida podem influenciar na determinação do tipo de crime a ser praticado, ou seja, as vítimas foram escolhidas pelas suas características, condições socioeconômicas, hábitos, características familiares e dos locais onde vivem. Em relação aos resultados da tipologia e aspectos do crime econômico, a pesquisa constatou que 50,38\% dos entrevistados cometeram crime de roubo, $27,48 \%$ de latrocínio, $26,72 \%$ de tráfico de 
drogas, $16,8 \%$ de furto, $2,3 \%$ de estelionato, $1,9 \%$ de seqüestro, $1,53 \%$ de extorsão e $6,1 \%$ de outros.

Neste sentido, Pezzin (1986) argumenta que o criminoso pode ser economicamente motivado pela análise do custo/benefício do delito, sendo que a opção de menor custo para a obtenção da quantidade eficiente de delitos envolve decisões de alocação de recursos em todos os setores que afetam tal atividade criminal.

A reincidência da prática criminosa ficou constatada na pesquisa, pois $65,27 \%$ dos entrevistados eram reincidentes e, na grande maioria, no mesmo tipo de crime. Este percentual é superior ao apontado pelo Ilanud (ONU), que mostra que $45 \%$ dos presos brasileiros, que cumpriram pena em cadeia, tornaram-se reincidentes (CRIME e CASTIGO, 1999). Este dado da pesquisa $(65,27 \%)$ é superior também à média paranaense, que, nos últimos anos (2000-2004), teve reincidência de presos de $31,38 \%$. Esta reincidência tem a ver com aspectos que os criminosos possuem, ou seja, uma tendência a reincidir após terem ingressado na "indústria" do crime, admitindo-se que a experiência na atividade criminal leve a uma redução nos custos de execução dos delitos, diminuição nos custos morais envolvidos e a menores custos de oportunidade, devido ao estigma e à perda de capital humano que um ex-criminoso enfrenta no mercado legal (FAJNZYLBER e ARAUJO JR, 2001).

Por outro lado, a reincidência da prática criminal pode ser inferida como um dos indicadores da ineficácia dos mecanismos de controle social e, também, como um reflexo da insuficiência das medidas preventivas e repressivas utilizadas pelo Estado para combater o crime econômico (FERNANDES e FERNANDES, 1995).

O comportamento criminoso vinculado a outras associações simbólicas relaciona o uso da arma de fogo na prática do crime econômico, uso associado à idéia de ganho fácil, conquista de mulheres, enfrentamento da morte, e concepção de um indivíduo completamente livre, o que revela que as práticas no mundo do crime vinculam-se a atos da virilidade (ZALUAR, 2004). Conforme dados obtidos nesta pesquisa, $55,73 \%$ dos entrevistados possuíam arma de fogo, e $48,09 \%$ destes fizeram uso da mesma na prática da atividade criminosa.

No aspecto da prática criminosa, o crime pode ser praticado por um individuo isoladamente ou de forma coletiva (organização). Os indivíduos agem individualmente quando os resultados da ação "[...] individual e independente podem servir aos interesses do indivíduo tão bem, ou melhor, do que uma organização" (OLSON, 1999, p. 19). Em relação a isto - a ação dos criminosos no tocante à formação de grupos -, dados da pesquisa demonstram que $72,52 \%$ agiam em grupo e 
$27,48 \%$ agiam isoladamente, ou seja, não possuíam parceiros para a prática criminosa.

O crime organizado é uma criminalidade difusa, que se caracteriza pela ausência de vítimas individuais, pela pouca visibilidade dos danos causados, bem como por um novo 'modus operandis' (profissionalidade, divisão de tarefas, participação de 'gente insuspeita', métodos sofisticados etc.) (HASSEMER, 1994, p. 85, citado por Gomes e Cervini, 1995, p. 56).

Destaca-se, neste aspecto, a observação espontânea do pesquisador ao perceber o receio ("tendenciosidade") de respostas nesta pergunta específica, haja vista a possibilidade de colocar em risco o "parceiro" que porventura ainda atue em atividades ilegais.

Assim, é preciso considerar que o crime organizado possui certa estrutura empresarial para a realização de atividades ilícitas, articulando fatores de produção (capital, pessoal e especialização tecnológica) e com os ganhos obtidos organizam empreendimentos lícitos, para transformar a renda ilícita em renda lícita, com o objetivo de encobrir as operações criminosas e justificar o volume de capital perante o fisco. É um crime constituído de importantes homens de negócios de vida aparentemente irrepreensível (FERNANDES e CHOFARD, 1995).

Muitos dos indivíduos que cometeram crime $(24,43 \%)$ conheciam a vítima, e $75,57 \%$ disseram não conhecer as vítimas. Porém, segundo as respostas dos entrevistados, os ambientes, os hábitos e as evidências externas de riqueza das vítimas eram consideradas como "iscas" para a atuação dos mesmos. Cumpre dizer que estes indivíduos são comumente racionais e impetuosos, oportunistas diante de um ambiente propício e factível, e sem nenhuma preocupação com o lado moral do negócio ou com o bem-estar social (BRENNER, 2003). Por outro lado, o modelo comportamental (GLAESER et al., 1996) realça que a alta variância nas taxas de crime através do espaço é evidểncia da existência de interações sociais entre os criminosos. Neste caso, os indivíduos cometem crimes em função de seus próprios atributos e das decisões de seus vizinhos.

Os fatores motivacionais que levaram os entrevistados a praticarem as atividades criminosas foram os mais diversos. Contudo, destacaram-se: a) a indução de "amigos" (influência negativa de grupos e/ ou de terceiros), apontada por $32,44 \%$; b) a cobiça/ambição/ganância, por $23,28 \%$; c) manter o sustento do vício, por $19,08 \%$; d) a inconseqüência e desejo de aventura, por 14,12\%; e) a dificuldade financeira (endividado, por exemplo) e a idéia do ganho fácil, apontada por $11,83 \%$ dos entrevistados; f) ajudar no orçamento familiar, pois estava desempregado, por $10,3 \%$; g) a falta de estrutura e orientação familiar (despreparo para a vida), por $9,16 \%$; h) motivos fúteis (embriaguez, falta de perspectiva etc.), por $8,78 \%$; i) ajudar no orçamento familiar, 
pois o dinheiro não dava para as despesas (empregado), por 7,25\%; j) manter o status, para $6,1 \%$; l) a inveja, por $1,15 \%$; e outras causas além das já citadas foram apontadas por $6,1 \%$ dos entrevistados.

Analisando melhor estes resultados, cabe citar algumas reflexões. Observou-se que a influência de "amigos" foi um fator determinante para $32,44 \%$ dos entrevistados migrarem para o crime. Porém, quando perguntado sobre a existência de algum parente e/ou conhecido próximo que tenha influenciado o entrevistado na prática do crime, constatou-se que a maioria $(51,35 \%)$ sofreu algum tipo de influência. Esta constatação fortalece a tese de interações sociais e reforça o fato da importância da relação família/crime não apenas em simples composição, mas através da inter-relação existente entre os membros que a compõem, no sentido de repassar os "bons" ou "maus" costumes aos seus membros.

Outro aspecto importante a destacar é que a maioria dos entrevistados estava trabalhando na época da prática do crime. Contudo, a associação da criminalidade ao baixo nível de escolaridade foi confirmada. Este cenário conjunto demonstra que melhores empregos com maiores remunerações podem influenciar negativamente o ingresso do indivíduo para a prática do crime econômico. O subemprego, através do baixo salário, por si insuficiente à manutenção própria ou da família, não deixa de ser, por suas características marcantes, de instabilidade pessoal e socioeconômica, um fator a mais a influenciar a curva ascendente da delituosidade (FERNANDES e FERNANDES, 1995). Vale frisar que dados da pesquisa indicaram que a dificuldade financeira, $o$ desemprego e a necessidade de ajudar no orçamento familiar contribuíram para que $29,38 \%$ dos entrevistados praticassem crimes.

Confirmando dados já expostos, os jovens ingressam para o mundo do crime, segundo Zaluar (2004), pelo uso de drogas - extorquidos e criminalizados -, e acabam nas mãos de traficantes e assaltantes, transformando-se em vítimas, devido à cobrança de dívidas, divisão dos lucros com policiais corruptos, ou se integram ao crime organizado e a grupos de extorsão.

Assim, os motivos que levaram à prática do crime econômico são de cunho social, de natureza conjuntural/estrutural, ligados a causas individuais, geralmente consideradas de natureza socioeconômica e psíquica (a cobiça, a ambição, o ganho fácil, a inveja, a indução de amigos; o desemprego, as dificuldades financeiras, a falta de estrutura familiar, entre outras).

\subsection{Perfil socioeconômico dos entrevistados na época da prática do crime}

Numa sociedade capitalista, de modo geral, as ocupações com melhores remuneraçōes demandam maior nível de escolaridade. Ao 
analisar as profissões da época da prática criminosa dos entrevistados, constataram-se, salvo raras exceções, profissões com pouca formação educacional. Neste aspecto, em decorrência da baixa escolaridade dos entrevistados (ocorrência maior de até ensino fundamental $-1^{\circ}$ grau - com $85,12 \%$ ), a maioria das atividades profissionais relacionadas sugere baixos níveis salariais. Isto favorece a tese de que a teoria econômica do crime esteja também associada a problemas estruturais e conjunturais.

Nesta mesma concepção, resultados da pesquisa ressaltam os estudos apontados anteriormente, no que diz respeito ao expressivo percentual de entrevistados, que, na época da prática do crime, estavam trabalhando $(68,7 \%)$, embora $10,3 \%$ dos entrevistados tenham relatado, como motivo para a prática do crime, o fato de estarem desempregados.

Portanto, a relação crime/desemprego não se apresentou de maneira relevante neste estudo, pois a maioria dos indivíduos que praticaram atividades criminosas estava empregada. Ressalta-se que a taxa de desemprego do Estado do Paraná, segundo o Instituto Paranaense de Desenvolvimento (IPARDES, 2005), era de 6,4\% para o mês de dezembro/2002, de $6,5 \%$ para o mês de dezembro/2003, de $7,2 \%$ em dezembro/2004 e 7,6\% para julho/2005.

Analisando a questão do percentual dos entrevistados que declararam estar trabalhando na época da prática do crime $(68,7 \%)$, destes, apenas um pequeno percentual $(29,39 \%)$ possuía registro na Carteira de Trabalho e Previdência Social (CTPS).

Ao indagar se a renda percebida pelos entrevistados era suficiente para manutenção de suas despesas básicas, 60,3\% afirmaram positivamente, ou seja, a renda percebida era suficiente para custear as despesas básicas da família. Cumpre dizer que a renda média declarada pelos entrevistados aproximava-se de 3,2 salários mínimos bruto ( $\mathrm{R} \$ 960,00$, mas com considerável desvio padrão). Isto reforça a tese de que pessoas migram para as atividades consideradas ilícitas por outras razões mais fortes, como influência de "amigos", e de natureza individual (cobiça e ambição; ganho fácil e manutenção de status), na esperança de que os ganhos esperados superem a renda oriunda das atividades lícitas.

Cumpre dizer que na concepção de Becker (1968), referendada em Balbinotto Neto (2003), os indivíduos se tornam criminosos porque os benefícios de tal atividade são compensadores, quando comparados com outras atividades ilegais, levando em conta os riscos, a probabilidade de apreensão, de condenação e a severidade da pena imposta. Vale ressaltar que um indivíduo, ao descartar uma renda garantida, optando por um ativo de risco com a mesma renda esperada ou maior, é considerado amante do risco (PINDYCK e RUBINFELD, 1994). Constatou-se assim que os criminosos migraram para atividades ilegais na esperança de que os ganhos esperados superassem os custos. 
Ainda em relação às condições socioeconômicas dos entrevistados, verificou-se que $48,85 \%$ dos mesmos possuíam bens imóveis. Ao correlacionar esses dados com a faixa etária, o grau de escolaridade, as atividades desenvolvidas e a renda, constata-se que, dificilmente, o indivíduo mudaria suas condições de vida na atividade legal da economia. Esta constatação vem ao encontro da hipótese desenvolvida por Fajnzylber (2000), de que os criminosos atribuem um valor monetário ao crime, e comparam este valor ao custo monetário envolvido na realização do mesmo.

Ao estudar a economia e o crime nos Estados de Minas Gerais, Rio de Janeiro e São Paulo, Andrade e Lisboa (2000b) constataram que o aumento do salário real faz com que os indivíduos que praticaram crimes retornem para as atividades legais, reduzindo a sua participação em atividades ilegais. Portanto, numa sociedade capitalista, alguns crimes funcionam como respostas racionais à estrutura das instituições sobre as quais as sociedades se articulam.

\subsection{Resultados da atividade criminosa}

Os dados da pesquisa demonstraram que a maioria dos entrevis. tados tinha alta percepção do grau de risco que estavam incorrendo quando da prática da atividade ilegal, pois, para $41,59 \%$, o grau de risco era superior a sete (numa escala de 0 a 9). Para $24,82 \%$, o grau de risco oscilava entre 4 a 6 , considerado risco moderado. Para os demais, $33,59 \%$, o grau de risco era inferior a quatro. No entanto, para este grupo de entrevistados, o risco não representava perigo, pois consideravam a atividade como normal.

No geral, pode-se dizer que, mesmo tendo pouca escolaridade, a maioria dos entrevistados sabia, sim, do risco da atividade ilegal que estavam praticando.

Beato, Peixoto e Andrade (2004), com enfoque particular, observaram que, na prática do crime econômico, as vítimas sāo selecionadas dentre aquelas que oferecem menor possibilidade de resistência, o que representa menor risco de aprisionamento para o agressor. Por outro lado, aquelas vítimas que proporcionam maior retorno econômico esperado são selecionadas pelos criminosos que são amantes do risco, uma vez que, por um mesmo risco de aprisionamento, o criminoso pode ganhar muito mais.

O insight da racionalidade do indivíduo que comete crime econômico também foi constatado por estudos desenvolvidos por Borilli (2001) e Schaefer e Shikida (2001), evidenciando a relação de risco na estrutura de mercado do crime, sendo que, na atividade criminal, está implícito o princípio hedonístico do máximo ganho com o mínimo de 
esforço, isto para variados graus de risco (FERNANDEZ, 1998). Por conseqüência, confirma-se também o que expôs Pindyck e Rubinfeld (1994), isto é, alguns criminosos são apreciadores do risco, especialmente quando cometem assaltos com grandes possibilidades de apreensão e punição - isto para valores individualizados do risco.

Quanto ao malogro ou sucesso na atividade ilegal, dentre os entrevistados, cerca de $27,87 \%$ disseram não ter obtido sucesso em sua atividade criminosa e $72,13 \%$ obtiveram algum sucesso. O insucesso da atividade criminosa, segundo os entrevistados, decorreu dentre outros, devido a fatores como: dedo duro (alcagüete - pessoa que delata outra), para 43,9\%; a ação da polícia, para 37,4\% e a falha própria descuido, bobeira -, para 19,85\% (Tabela 1). Isto demonstra, de certa forma, a fragilidade das organizações individuais e coletivas pesquisadas no tocante ao crime econômico como atividade ilícita, e/ou ressalta uma certa eficiência dos aparatos institucionais responsáveis pela repressão do crime.

Tabela 1. Fatores que levaram ao insucesso de sua atividade criminosa

\begin{tabular}{l|c|c}
\hline Fatores do insucesso & Quantidade & $\%$ \\
\hline Traição & 11 & 4,2 \\
Dedo-duro (alcagüete) & 115 & 43,9 \\
Falha própria/pessoal & 52 & 19,85 \\
Falha do parceiro & 14 & 5,34 \\
Ação da polícia & 98 & 37,4 \\
Sistema de proteção eficiente & 4 & 1,52 \\
Reação bem sucedida da(s) vítima(s) com uso de arma & 0 & 0 \\
Reação bem sucedida da(s) vítima(s) sem uso de arma & 5 & 1,9 \\
Outros & 17 & 6,49 \\
\hline
\end{tabular}

Fonte: Dados da pesquisa (2005)

Outros sim, como destaque percebido na condução das entrevistas, o insucesso a que se refere o entrevistado não está correlacionado com a punibilidade, mas ao retorno econômico não alcançado.

Neste contexto, a análise econômica do crime baseia-se fortemente na relação delito/punição como determinante da taxa criminal, em que a eficácia policial e judicial se relaciona com a possibilidade de os benefícios da atividade criminosa suplantarem seus custos e compensarem o risco estipulado (FERNANDEZ, 2003; BALBINOTTO NETO, 2003). Por isso, a pena deve ter a função de punir, coibir e intimidar. $A$ pena deve ser superior ao retorno econômico esperado pelo criminoso, para que a mesma tenha eficácia e possa coibir o ingresso e a permanência (reincidência) na atividade ilícita (FERNANDES e FERNANDES, 1995). O tempo gasto pelo criminoso em atividades ilegais é uma perda social, uma vez que esse mesmo tempo poderia ser utilizado de forma legal. Assim, a conclusão de que o crime não deve compensar é a solução ótima a ser perseguida pela sociedade (BRENNER, 2001). 
Não obstante, ao analisar os dados quanto ao retorno econômico esperado num grau de 0 a 9 (considerando como a obtenção máxima do retorno esperado o grau 9), verificou-se que $19,86 \%$ dos entrevistados, não alcançou nenhum sucesso na prática da atividade ilícita; para $16,41 \%$ dos entrevistados, o retorno ficou abaixo do esperado (entre 1 e 3); para $23,28 \%$, o retorno esperado ficou entre 4 e 6 . Porém, para $40,45 \%$ dos entrevistados, o retorno econômico esperado da atividade criminosa foi superior a 7. Isto demonstra que a probabilidade de se obter êxito na atividade ilegal pode ser considerada significativa, principalmente se for considerado o risco da mesma e o variado grau de organização declarado pelos entrevistados.

No decorrer das entrevistas, observou-se que alguns réus pesquisados, embora estivessem cerceados de sua liberdade de ir e vir, estavam, de certa forma, "satisfeitos" com os ganhos obtidos com o crime econômico.

De fato, o sucesso da atividade ilegal, assim como da atividade legal - numa sociedade capitalista -, está correlacionado com o lucro. Portanto, o empresário - do setor ilegal - é o sujeito que organiza sua atividade, reunindo os fatores de produção disponíveis e assumindo os riscos inerentes à atividade efetuada, podendo perceber lucros ou incorrer em prejuízos que, neste último caso, podem culminar na punibilidade - cerceamento de liberdade (SCHAEFER e SHIKIDA, 2001).

Os resultados da pesquisa também apontaram que, para $80,14 \%$ dos entrevistados, a atividade criminosa resultou em algum grau de sucesso, sendo que, para $19,47 \%$ destes, o retorno da prática criminosa atingiu o grau máximo - igual a 9.

Em função desses apontamentos, procurou-se testar os resultados ora obtidos por meio de uma análise estatística mais rigorosa, sendo feito um Teste $t$ de duas amostras em par para médias. ${ }^{4}$

$O$ Teste t para duas amostras em par e para médias (foi comparada a questão do risco econômico e dos seus vários níveis - de 0 a 9 -, apontados pelos réus vis-à-vis, o retorno econômico e dos seus vários níveis - de 0 a 9 -, também apontados pelos réus) mostrou que, na média, risco e retorno se igualam, para um nível de significância de $5 \%$. Neste caso, segundo Schaefer e Shikida (2001), se, na média, risco e retorno se igualam (a mesma idéia de indiferença entre o recebimento de uma renda garantida e o recebimento de uma renda incerta,

\footnotetext{
${ }^{4}$ Foi utilizada, neste cálculo, a equação que se segue:

$t={ }^{x}-\mu_{0}$

Em que: $t=$ valor calculado; $\bar{x}=$ média da amostra; $\mu_{0}=$ média da população; $s=$ desvio padrão da amostra; $n=$ tamanho da amostra.
} 
mas que apresente a mesma esperada), e sendo a base familiareducacional-socioeconômica dos detentos considerada frágil, a migração para o crime torna-se factível. $E$ isto não deixa de ser um fator preocupante neste estudo.

Isto posto, os dados da pesquisa reportam ao argumento básico da abordagem econômica do crime ao considerar que os infratores reagem aos incentivos, tanto positivos quanto negativos, e que $o$ número de crimes econômicos cometidos é influenciado pela alocação de recursos públicos e privados para fazer frente ao cumprimento da lei e de outros meios de coibi-los. Porquanto, de acordo com Balbinotto Neto (2003), o crime econômico é um grave problema para a sociedade, em certa medida vale a pena cometê-los; isto implica significativos custos em termos sociais.

\subsection{Avaliação do funcionamento do sistema de justiça pelos entrevistados}

A eficácia do sistema de justiça, na prevenção do crime econômico, pode contribuir na redução da incidência dos crimes. Para tanto, a ação deve ser justa, aplicada de modo infalível e rápido, do contrário, é bem provável que instigue a atividade criminosa através da sensação de impunidade, deixando de alcançar a real função de intimidar ou desmotivar os criminosos.

Em relação ao funcionamento do sistema de justiça, a maioria dos entrevistados $(77,1 \%)$ considerou as atividades policiais ineficientes para coibir a atividade criminosa, enquanto $22,9 \%$ consideraram essas atividades como eficientes. A fundamentação utilizada pelos entrevistados quanto ao descrédito foram basicamente: a corrupção, o envolvimento dos agentes da polícia com o crime organizado, a inadequação do trato policial para com os criminosos e a falta de equipamentos (viaturas e outros).

De acordo com Silva e Gall (2002), algumas das causas do crescimento da criminalidade estão nas estruturas institucionais atrofiadas e na falha dos chefes de polícia, lobistas e "líderes", com pouca ou nenhuma experiência em polícia. Corroborando, Caldeira (1991) informa que, não somente os criminosos transgridem a lei, mas também a Justiça não funciona, a polícia falha e desrespeita a lei.

Atualmente, tem-se clareza que a pena de prisão é cara e ineficaz; não inibe a criminalidade, não reeduca o agente delituoso e, muitas vezes, estimula a reincidência. Criminosos que já cumpriram penas saem das penitenciárias, em geral, piores e, ao reincidirem, cometem crimes mais graves (LEMGRUBER, 2002).

Por outro lado, verificou-se anteriormente que $37,4 \%$ dos entrevistados apontaram a ação da polícia como fator que levou ao insucesso da atividade criminosa, e, para 19,86\% dos entrevistados, a atividade 
criminosa não propiciou o retorno econômico esperado. Para esses dois grupos de entrevistados, pode-se inferir a velha máxima criminal: "o crime não compensa".

O sistema judiciário também foi apontado como fator de insucesso da atividade criminosa, devido às disparidades existentes entre a pena e o tipo de crime praticado, ou seja, algumas penas são muito longas, outras, muito severas em relação ao dano social causado. No entanto, muitos indivíduos que praticaram crimes, que deveriam estar cumprindo pena, estão usufruindo do status social do cargo público que exercem para beneficio próprio, segundo os entrevistados.

Ainda em relação ao sistema judiciário, a lentidão, a falta de informações sobre os processos, a demora na revisão dos processos, a falta de assistência social e jurídica e a inadequação das instalações (sistema prisional) são fatores apontados para o descrédito do mesmo. Segundo Silva e Gall (2002), em relaçāo ao sistema judiciário, observa-se, por exemplo, o reduzido número de juízes existentes no Brasil (1 para 23 mil habitantes, na Alemanha, há 1 para 3,5 mil habitantes), bem como ritos judiciais ultrapassados, burocratizados, entre outros.

O descrédito no sistema judiciário contribuiu para 50,38\% dos entrevistados tentarem fuga nas instituições prisionais em que cumpriam pena. Fatores relacionados à falta de assistência médica e jurídica foram apontadas como motivos para a fuga. O cenário justifica o elevado número de fugas e a facilidade de entrada de drogas (segundo pesquisa, $15,27 \%$ dos entrevistados afirmam ainda consumir drogas). Armas e telefones celulares que entram nas cadeias apontam para níveis de corrupção muito preocupantes. O crime econômico oriundo de novos fenômenos, como criminalidade organizada, e os crimes do poder (criminalidade econômica e financeira do poder público) não são contemplados com eficácia pelo atual sistema judiciário. O crime organizado, como no caso do narcotráfico, impôs um novo paradoxo: "[...] o Estado tem de se desnacionalizar e transnacionalizar o seu poder coercitivo e repressivo para que possa tratar dos seus problemas nacionais" (MIR, 2004, p. 388).

Outra constatação da pesquisa, que deve ser ressaltada no que tange à punibilidade, mostrou que, entre os entrevistados, 33,97\% manifestaram-se a favor da instituição da pena de morte, e 66,03\% contrários à mesma. Embora cerceados de liberdade, é expressivo o percentual favorável à instituição da pena de morte. Isto se justifica pelo fato de eles acreditarem que a pena de morte não se aplica ao tipo de crime por eles praticado, mas aos crimes de maior gravidade tipificados pela legislação como "crimes hediondos" (exceto tráfico de drogas, não considerado "hediondo"). 


\subsection{Fatores que podem diminuir a criminalidade na concepção dos}

entrevistados

Em relação ao que poderia ser feito para diminuir os crimes de natureza econômica, os entrevistados, na sua maioria, apontaram para: mais educação profissionalizante; mais empregos com maior remuneração; mudança na legislação - penas mais severas -; políticas eficazes no combate ao tráfico de drogas - acabar com o comércio de drogas -; assistência ao egresso - acabar com os preconceitos, discriminação do ex-presidiário, o estigma de o preso ser identificado ou rotulado como desviante limita suas oportunidades socioeconômicas.

Correlacionando os fatores apontados para redução do crime econômico pelos entrevistados com os dados apontados anteriormente, em que $85,12 \%$ dos entrevistados possuem até ensino fundamental ( $1^{\circ}$ Grau), e $68,7 \%$ dos entrevistados estavam trabalhando na época da prática do crime, fica evidente que a relação crime/desemprego não se verifica tão fortemente nesta pesquisa, pois a maioria desses indivíduos que cometeram crimes econômicos estava trabalhando. Outrossim, corrobora-se a importância dos investimentos em educação e nas melhores oportunidades de empregos - mas, vale dizer, com maior remuneração -, como forma de diminuir, coibir os crimes de natureza econômica, segundo os entrevistados.

\section{Considerações finais}

Como corolário deste estudo, não se rejeitou a hipótese de que os criminosos migraram para as atividades ilegais na esperança de que os ganhos esperados superassem os riscos da atividade. A opção pela prática do crime de natureza econômica é uma decisão individual tomada racionalmente, com ou sem influência de terceiros, em face da percepção de custos e benefícios, assim como os indivíduos fazem em relação a outras decisões de natureza econômica. Os criminosos agem individualmente quando os resultados da ação criminosa servem aos seus interesses tão bem, ou melhor, que a ação coletiva.

Esta confirmação, no entanto, deve ser relativizada, porquanto neste estudo existe o problema de viés de seleção da amostra, que considera pessoas que praticaram crimes e que foram presas. É possível que muitas pessoas que praticam crimes e que não são presas tenham características socioeconômicas próprias devido a possíveis problemas institucionais como corrupção. Logo, este estudo está retratando as características dos criminosos que são presos, e não dos criminosos 
em geral. Dessa forma, os resultados apontam para o que leva alguém a cometer um crime (e que foi efetivamente preso).

Last but not least, como esta pesquisa tratou-se de um estudo de caso fundamentado em questionários aplicados a pessoas que estão cumprindo pena em três estabelecimentos carcerários do Paraná, valendo-se fundamentalmente de dados primários (que são poucos na área da economia do crime no Brasil), sugere-se, como futura extensão deste trabalho, que mais pesquisas possam ser implementadas para examinar novas contextualizações em níveis que esta amostra não possibilitou conclusões.

\section{Referências}

ADORNO, S. et al O jovem e a criminalidade urbana de São Paulo. São Paulo: Fundação SEADE/Núcleo de Estudos da Violência, 1995.

ANDRADE, M. V.; LISBOA, M. de B. A violência como causa de mortalidade. Conjuntura Econômica, Rio de Janeiro, v. 54, n. 5, p. 61-64, maio 2000a.

ANDRADE, M. V.; LISBOA, M. de B. Desesperança de vida: homicídios em Minas Gerais, Rio de Janeiro e São Paulo: 1981 a 1997. Rio de Janeiro: FGV, 2000b. Mimeografado.

BALBINOTTO NETO, G. A teoria econômica do crime. Revista Leader, Porto Alegre, ed. 35, fev, 2003. Disponivel em: <http://www.iee.com.br/leader/edicao_35/ index.asp > . Acesso em: 16 jan. 2005.

BEATO, C. F.; PEIXOTO, B. T; ANDRADE, M. V. Crime, oportunidade e vitimização. Revista Brasileira de Ciências Sociais, São Paulo, v. 19, n. 55, p. 73-89, Jun. 2004.

BECKER, G. S. Crime and punishment: an economic approach. Journal of Political Economy, Chicago, v. 76, n.1, p. 169-217, 1968.

BECKER, H. S. Estudo de praticantes de crimes de delitos. In: - Métodos de pesquisa em ciências sociais. 4. ed. São Paulo: HUCITEC, p. 153-178, 1999.

BORILLI, S. P. Evidências empíricas de crimes lucrativos a partir de estudos na Penitenciária Industrial de Guarapuava e Cadeia Pública de Foz do Iguaçu (PR). 2001. 57 f. Dissertação (Mestrado em Ciências Aplicadas) - Faculdades de Palmas. Palmas, 2001.

BORILLI, S. P. ; SHIKIDA, P. F. A. Apontamentos acerca das organizações criminosas a partir de um estudo exploratório na Penitenciária Industrial de Guarapuava e Cadeia Pública de Foz do Iguaçu (Paraná). In: ENCONTRO PARANAENSE DE ECONOMIA, III, Maringá. Anais... Maringá: UEM, 2002. 1 CD-ROM.

BRANDT, V. C. O trabalhador preso no Estado de São Paulo. São Paulo: CEBRAP, 1986.

BRENNER, G. A racionalidade econômica do comportamento criminoso perante a ação de incentivos. Tese (Doutorado em Economia) - IEPE, Universidade Federal do Rio Grande do Sul, Porto Alegre, 2001.

BRENNER, G. A teoria econômica do crime. Revista Leader, Porto Alegre, ed. 35, fev. 2003. Disponivel em: <http://www.iee.com.br/eader/edicao_35/index.asp >. Acesso em: 6 jan. 2005.

CALDEIRA, T. P. Direitos humanos ou "privilégio de bandidos"?: desventuras da democratização brasileira. Novos Estudos Cebrap, São Paulo, n. 30, p. 162-174, jul, 1991. 
COHEN, L.; FELSON, M. Social change and crime rate trends: a routine approach. American Sociological Review, New York, 44, p. 588-608, 1979.

CRIME e castigo. Veja, São Paulo, p. 46-47, out, 1999.

EHRLICH, 1. Crime, punishment, and the market for offenses. The Journal of Economic Perspectives, Nashville, Tenn., US, v. 10, p. 43-67, 1996.

ENGEL, L. E. F. A economia do crime no Paraná: um estudo de caso na Penitenciária Industrial de Cascavel. 2003. $54 \mathrm{f}$. Monografia (Bacharelado em Ciências Econômicas) - CCSA/UNIOESTE, Toledo, 2003.

FAJNZYLBER, P. Determinantes econômicos da criminalidade: notas para uma discussão. RJ: IPEA, 2000.

FAJNZYLBER, P.; ARAUJO JR, A. de. Violência e criminalidade. Rio de Janeiro: IPEA, 2001.

FERNANDES, N. ; CHOFARD, G. Sociologia criminal. São Paulo: Rumo, 1995.

FERNANDES, N. ; FERNANDES N. Criminologia integrada. São Paulo: Revista dos Tribunais, 1995.

FERNANDEZ, J. C. A economia do crime. Revista Leader. Edição n.35. Fev/2003 Disponivel em: <http://www.iee.com.br/leader/edição_35/index.asp >. Acesso em: 6 jan. 2005.

FERNANDEZ, J. C. A economia do crime revisitada. Economia 8 Tecnologia. Campinas, v. 1, n. 03, Jul.-Set./. p. 36-44, 1998.

GIL, A. C. Técnicas de pesquisa em economia e elaboração de monografias. São Paulo: Atlas, 2000.

GLAESER, E. L. et al. Crime and social interactions. The Quarterly Journal of Economics, Cambridge, v. 111, n.2, p. 507-548, may, 1996.

GODOY, A. S. Pesquisa qualitativa e sua utilizaçāo em administração de empresas. Revista Administração de Empresas, São Paulo, v.35, n. 4, p. 65-71, out./dez, 1995.

GOMES, L. F. ; CERVINI, R. Crime organizado: enfoques criminológico, jurídico: (Lei $\mathrm{n}^{\circ}$ 9.034/95) e político-criminal. São Paulo: Revista dos Tribunais, 1995.

HASSEMER, W. Perspectivas de uma moderna política criminal. In: IBCCrim (08). SP: RT/IBCCrim, p. 89, 1994.

IBGE. Estatística. Disponível em: < http://www1 ibge.gov.br/ibgeteen/pesquisas/ estados-brasil html >. Acesso em: 11 jun. 2001.

IB TEIXEIRA. O alarmante custo da violência. Dinheiro na Web, São Paulo, n. 139, 13 out. 2005. Entrevista concedida a Simone Goldberg. Disponível em: http://terra.com.br/ dinheiro na web/139_01.htm. Acesso em: 18 Out, 2005.

IPARDES. Estudos e pesquisas. Disponivel em: <http:/www.ipardes.gov.br/>. Acesso em: 30 Abr, 2005.

LEMGRUBER, J. Problematizando temas relativos ao sistema penitenciario - FÓRUM DE DEBATES - Criminalidade, Violência e Segurança Pública no Brasil: Uma Discussão sobre as Bases de Dados e Questōes Metodológicas $2^{\circ}$ Encontro: Julgamento e penalização/ Sistema Judiciário; Sistema Judiciário; Execução das penas e reinserção/ Sistema penitenciário, IPEA, 2000

LEMGRUBER, J. Controle da criminalidade: mitos e fatos. Revista Think Tank, São Paulo, ano 5, n. 15, p. 3-20, jun./ago. 2002.

MIR, L. Guerra civil: estado e trauma. São Paulo: Geração Edito ' ol, 2004.

OLSON, M. A lógica da ação coletiva: os benefícios públicos e unıa teoria dos grupos sociais. São Paulo: Edusp, 1999.

142 Revista Análise Econômica, Porto Alegre, ano 24, n. 46, p. 123·144, setembro de 2006. 
PEZZIN, L. E. Criminalidade urbana e crise econômica: o caso de São Paulo. São Paulo: IPE/USP, 1986.

PINDYCK, R. S.; RUBINFELD, D. L. Microeconomia. São Paulo: MakronBooks, 968 p, 1994.

SCHAEFER, G. J.; SHIKIDA, P. F. A Economia do crime: elementos teóricos e evidências empíricas. Análise Econômica, ano 19, n. 36, p.195-217, setembro, 2001.

SHIKIDA, P. F. A. Economia do crime: teoria e evidências empíricas a partir de um estudo de caso na Penitenciária Estadual de Piraquara (PR). Relatório de pesquisa (Edital Universal do CNPq), 2005.

SILVA, J.V.; GALL, N. Incentivos perversos à segurança pública. In: OLIVEIRA, N. V. (Org). Insegurança pública: reflexões sobre a criminalidade e a violência urbana. São Paulo: Nova Alexandria, 2002.

VIÉGAS, F. Violência e crime. Análise Financeira, 2004. Disponível em: <http:// www.analisefinanceira.com.br/artigos/economiadocrime.htm>. Acesso em: 18 jan, 2005.

YIN, R. K. Estudo de caso: planejamento e métodos. Porto Alegre: Bookman, 2001.

ZALUAR, A. Integração perversa: pobreza e tráfico de drogas. Rio de Janeiro: FGV, 2004. 